\title{
Review
}

\section{Identifying the Time to Change BCR-ABL Inhibitor Therapy in Patients with Chronic Myeloid Leukemia}

\author{
Michael R. Savona ${ }^{a} \quad$ Giuseppe Saglio $^{b}$

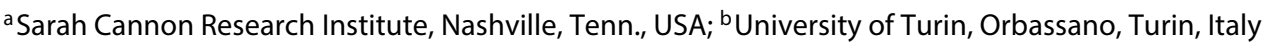

\section{Key Words}

BCR-ABL inhibitor · Chronic myeloid leukemia · Dasatinib · Imatinib · Nilotinib

\begin{abstract}
Many patients newly diagnosed with chronic myeloid leukemia in the chronic phase (CML-CP) respond to imatinib. Those experiencing imatinib resistance/intolerance require alternative treatments. Delayed responses increase the risk of transformation to advanced disease, mutation development and loss of response. In retrospective analyses, achieving faster, deeper responses correlated with improved longterm response and outcome. Changing therapy to obtain early responses may improve the depth and speed of response, ultimately improving the outcome. Although trials are ongoing, there are no prospective data indicating that changing from imatinib to later-generation inhibitors reverses the inferior prognosis and improves the outcome. We describe the rationale behind early therapy change in CML-CP.
\end{abstract}

Copyright $\odot 2013$ S. Karger AG, Basel

\section{Introduction}

Many patients with newly diagnosed chronic myeloid leukemia in chronic phase (CML-CP) are currently treated with imatinib, a BCR-ABL tyrosine kinase inhibitor, based on results from the pivotal phase III International
Randomized Study of Interferon versus STI571 (IRIS) trial $[1,2]$. After 8 years, the cumulative complete cytogenetic response (CCyR) rate for patients receiving imatinib was $83 \%$ [3]. The 5 - and 8 -year overall survival (OS) rates were 89 and $85 \%[3,4]$, respectively, compared with a 5 -year OS rate of $57 \%[2,5]$ in patients receiving interferon- $\alpha$ plus cytarabine in previous randomized studies performed before the availability of imatinib. This demonstrates one of the greatest achievements in modern allopathic medicine.

Nonetheless, approximately one third of patients develop resistance or do not respond to imatinib, which in many cases is because of the presence or emergence of BCR-ABL mutations for which imatinib has no inhibitory effect $[2,3,6,7]$. Further, some patients are intolerant of imatinib therapy as they experience persistent lowgrade adverse events (AEs) which impact their quality of life $[2,3,6,7]$. After an 8-year follow-up of the imatinib arm of the IRIS trial, $8 \%$ of patients lost complete hematologic response (CHR), 18\% lost CCyR, $8 \%$ transformed to accelerated-phase or blast-phase (AP/BP) CML, and $6 \%$ discontinued the trial based on treatment-related AEs $[3,8]$. When IRIS was conducted, there were limited treatment options available for CML-CP, and more patients may have continued study treatment despite persistent low-grade AEs or other events.

Although imatinib is an effective treatment for most patients with newly diagnosed CML-CP, some patients require alternative treatments because of intolerance or re-

\section{KARGER}

E-Mail karger@karger.com www.karger.com/aha
C 2013 S. Karger AG, Basel

0001-5792/13/1304-0268\$38.00/0
Michael R. Savona, MD, FACP

Director of Leukemia Research, Sarah Cannon Research Institute 3322 West End Ave, Suite 900

Nashville, TN 37203 (USA)

E-Mail msavona@tnonc.com 
sistance. An understanding of the mechanisms of imatinib resistance led to the development of newer BCR-ABL inhibitors, dasatinib, nilotinib, bosutinib, and ponatinib, which have increased specificity and/or potency for BCR$\mathrm{ABL}$ and are effective against a majority of clinically observed BCR-ABL mutations [9-15]. Dasatinib, nilotinib, bosutinib, and ponatinib have been approved for patients with imatinib-resistant or imatinib-intolerant CML-CP since 2006, 2007, September of 2012 (US only), and December of 2012 (US only), respectively [16-22].

Both dasatinib and nilotinib have superior response rates over imatinib in patients with newly diagnosed CML-CP as demonstrated in randomized, multicenter phase III trials [23, 24]. Following the phase III Dasatinib versus Imatinib Study in Treatment-Naïve CML patients (DASISION) and Evaluating Nilotinib Efficacy and Safety in Clinical Trials-Newly Diagnosed Patients (ENESTnd) trials, both dasatinib and nilotinib were approved in 2010 as first-line treatments for patients with newly diagnosed CML-CP $[17,20]$. Although a survival benefit has not yet been detected, 2-year follow-up of the DASISION and the ENESTnd trials showed that significant improvements in molecular remission rates for dasatinib and nilotinib over imatinib are maintained. In DASISION, the rates of major molecular response (MMR) were 64 versus $46 \%(\mathrm{p}<0.0001)$, and rates of molecular response $\geq 4.5 \log$ reduction in BCR-ABL levels $\left(\mathrm{MR}^{4.5}\right.$; BCR-ABLlevels $\leq 0.0032 \%)$ were 17 versus $8 \%(p=0.0032)$ for dasatinib $100 \mathrm{mg}$ once daily versus imatinib $400 \mathrm{mg}$ once daily, respectively $[25,26]$. After a 2-year follow-up of the ENESTnd trial, for nilotinib $300 \mathrm{mg}$ twice daily versus $400 \mathrm{mg}$ twice daily versus imatinib $400 \mathrm{mg}$ once daily, rates of MMR were 71 versus 67 versus $44 \%$ ( $p<0.0001$ for both comparisons), and rates of $\mathrm{MR}^{4.5}$ were 25 versus 19 versus $9 \%$ ( $\mathrm{p}<0.0001$ for nilotinib $300 \mathrm{mg}$ versus imatinib; $\mathrm{p}=0.0006$ for nilotinib $400 \mathrm{mg}$ versus imatinib), respectively [27]. These results demonstrate that dasatinib and nilotinib are effective treatments in the first-line setting for patients with CML-CP and are now included as first-line treatment options for patients with newly diagnosed CML-CP in the updated National Comprehensive Cancer Network (NCCN) and European Society of Medical Oncology (ESMO) guidelines [28, 29] and European LeukemiaNet (ELN) recommendations [30].

New evidence supports initial use of more potent second-generation BCR-ABL inhibitors to achieve improved long-term outcomes [23-25, 27, 31, 32]. A delayed reduction in BCR-ABL level or other measures of tumor burden, as determined by cytogenetic and molecular response, increases the risk of disease progression whereas

Time to Change BCR-ABL Inhibitor Treatment in CML a rapid reduction in tumor burden may have an additive value in reducing this risk [33-37]. Additionally, secondgeneration BCR-ABL inhibitors, which have notably broader mutational coverage than imatinib, may reduce the likelihood of emergent resistance, thereby further decreasing the risk of progression $[37,38]$.

With the advent of second-generation BCR-ABL inhibitors, the importance of achieving early, deep molecular and cytogenetic responses for long-term outcomes has received significant attention based on a number of exploratory, retrospective analyses in the first- and second-line treatment settings [31,39-47]. The most recent NCCN and ESMO guidelines advise a change in treatment [alternative BCR-ABL inhibitor or allogeneic hematopoietic stem cell transplant (alloHSCT)] or clinical trial (NCCN) if a patient does not reach a deep level of molecular response [BCRABL transcript level $\leq 10 \%$ on the International Scale (IS)] by 3 months $[28,29]$ or by 6 months according to the updated ELN recommendations [30]. Although a strong association between an early reduction in BCR-ABL transcript levels and improved survival has been indicated by several independent retrospective analyses, the benefit of changing treatments at these early time points has yet to be validated in a randomized clinical trial.

In this article, we review the current evidence for determining when to change BCR-ABL inhibitor therapy based on certain clinical indicators or measures of response, to support achievement of the best long-term outcomes and reduce the risk of transformation to advanced disease.

\section{Achieving an Early, Deep Response May Be Associated with Improved Long-Term Response and Outcome}

CML treatment recommendations incorporate the principle of achieving a specific level of response within a defined time frame [28-30]. Current CML treatment guidelines (NCCN, ESMO and ELN) define an optimal response, warning or suboptimal response and failure during first- and second-line treatment at specific treatment landmarks from 3 months up to and including 12 18 months (table 1) [28-30].

Independent studies have confirmed that patients on imatinib classified as having failure or suboptimal response at 3, 6 or 12 months, according to the 2009 ELN recommendations, have significantly worse outcomes than optimally responding patients [49-52]. These data suggest that increasing the proportion of patients who 
Table 1. Definitions of response during treatment with BCR-ABL inhibitors according to ELN recommendations (a), NCCN guidelines (b) and ESMO guidelines (c) [28-30]

a ELN recommendations [30]

\begin{tabular}{lll}
\hline Response & & \\
\cline { 2 - 4 } Optimal $^{1}$ & Warning $^{2}$ & Failure $^{3}$ \\
\hline
\end{tabular}

First-line BCR-ABL inhibitor therapy and second-line when first-line treatment changed for intolerance

\begin{tabular}{|c|c|c|c|}
\hline Baseline & NA & High risk or $\mathrm{CCA} / \mathrm{Ph}+$, major route & NA \\
\hline 3 months & $\begin{array}{l}\text { BCR-ABL } 1 \leq 10 \% \text { and/or } \\
\mathrm{Ph}+\leq 35 \%\end{array}$ & $\begin{array}{l}\text { BCR-ABL } 1>10 \% \text { and } / \text { or } \\
\text { Ph+36-95\% }\end{array}$ & No $\mathrm{CHR}$ and/or $\mathrm{Ph}+>95 \%$ \\
\hline 6 months & $\begin{array}{l}\text { BCR-ABL } 1<1 \% \text { and } / \text { or } \\
\mathrm{Ph}+0\end{array}$ & $\begin{array}{l}\text { BCR-ABL1 } 1-10 \% \text { and/or } \\
\text { Ph+ } 1-35 \%\end{array}$ & BCR-ABL1 $>10 \%$ and/or $\mathrm{Ph}+>35 \%$ \\
\hline 12 months & BCR-ABL $1 \leq 0.1 \%$ & BCR-ABL1 $0.1-1 \%$ & BCR-ABL1 $>1 \%$ and/or $\mathrm{Ph}+>0 \%$ \\
\hline Then, at any time & BCR-ABL $1 \leq 0.1 \%$ & $\mathrm{CCA} / \mathrm{Ph}-\left(-7\right.$, or $\left.7 \mathrm{q}^{-}\right)$ & $\begin{array}{l}\text { Loss of CHR; loss of CCyR; confirmed } \\
\text { loss of } \mathrm{MMR}^{4} \text {; mutations; CCA/Ph+ }\end{array}$ \\
\hline \multicolumn{4}{|c|}{ Second-line BCR-ABL inhibitor therapy } \\
\hline Baseline & NA & $\begin{array}{l}\text { No CHR or loss of CHR on imatinib, } \\
\text { or lack of CyR to first-line TKI, or } \\
\text { high risk }\end{array}$ & NA \\
\hline 3 months & $\begin{array}{l}\text { BCR-ABL } 1 \leq 10 \% \text { and } / \text { or } \\
\mathrm{Ph}+<65 \%\end{array}$ & $\begin{array}{l}\text { BCR-ABL1 }>10 \% \text { and } / \text { or } \\
\mathrm{Ph}+65-95 \%\end{array}$ & $\begin{array}{l}\text { No CHR, or } \mathrm{Ph}+>95 \% \text {, } \\
\text { or new mutations }\end{array}$ \\
\hline 6 months & $\begin{array}{l}\text { BCR-ABL } 1 \leq 10 \% \text { and } / \text { or } \\
\mathrm{Ph}+<35 \%\end{array}$ & $\mathrm{Ph}+35-65 \%$ & $\begin{array}{l}\text { BCR-ABL1 }>10 \% \text {, and/or } \mathrm{Ph}+>65 \% \text {, } \\
\text { and/or new mutations }\end{array}$ \\
\hline 12 months & $\begin{array}{l}\text { BCR-ABL } 1<1 \% \text { and } / \text { or } \\
\mathrm{Ph}+0\end{array}$ & $\begin{array}{l}\text { BCR-ABL1 } 1-10 \% \text { and/or } \\
\text { Ph+1-35\% }\end{array}$ & $\begin{array}{l}\text { BCR-ABL } 1>10 \% \text {, and/or } \mathrm{Ph}+>35 \% \text {, } \\
\text { and/or new mutations }\end{array}$ \\
\hline Then, at any time & BCR-ABL1 $\leq 0.1 \%$ & $\begin{array}{l}\text { CCA/Ph- }\left(-7 \text { or } 7 q^{-}\right) \text {or } \\
\text { BCR-ABL } 1>0.1 \%\end{array}$ & $\begin{array}{l}\text { Loss of CHR, or loss of CCyR or PCyR; } \\
\text { new mutations; confirmed loss of } \mathrm{MMR}^{4} \text {; } \\
\text { CCA/Ph+ }\end{array}$ \\
\hline
\end{tabular}

Reproduced with permission of the American Society of Hematology, from Baccarani et al. [30]; permission conveyed through Copyright Clearance Center, Inc.

b NCCN guidelines [28]

$\begin{array}{ll}\text { Response } & \\ \text { Optimal }^{1} & \text { Suilure }^{3}\end{array}$

First-line BCR-ABL inhibitor therapy

\begin{tabular}{llll}
\hline 3 months & $\begin{array}{l}\text { BCR-ABL } \leq 10 \% ; \\
\text { PCyR }(1-35 \%)\end{array}$ & - & BCR-ABL $>10 \% ;<$ PCyR \\
\hline 12 months & CCyR and MMR & PCyR $(1-35 \%)$ & $\begin{array}{l}\text { No MMR; }<\text { PCyR }(>35 \%) ; \text { cytogenetic } \\
\text { relapse }\end{array}$ \\
\hline 18 months & CCyR and MMR & - & $\begin{array}{l}\text { No MMR with no CCyR at } 12 \text { months; } \\
\text { PCyR (1-35\%); cytogenetic relapse }\end{array}$ \\
\hline
\end{tabular}


Table 1. (continued)

c ESMO guidelines [29]

\begin{tabular}{llll}
\hline & \multicolumn{2}{l}{ Response } & \\
\cline { 2 - 4 } & Optimal $^{1}$ & Warning $^{2}$ & Failure $^{3}$ \\
\hline First-line BCR-ABL & inhibitor therapy & & \\
\hline 3 months & $\mathrm{Ph}+\leq 95 \% ;$ & - & Ph+ $>95 \% ; \mathrm{BCR}-\mathrm{ABL}>10 \%$ \\
& $\mathrm{BCR}-\mathrm{ABL}<10 \%$ & $\mathrm{Ph}+35-65 \%$ & $\mathrm{Ph}+>65 \%$ BCR-ABL $>10 \%$ \\
\hline 6 months & $\mathrm{Ph}+\leq 35 \% ;$ & & Ph+ $\geq 1 \%$; BCR-ABL $>1 \%$ \\
\hline Any time & $\mathrm{BCR}-\mathrm{ABL}<10 \%$ & - & Loss of CHR; loss of CCyR; mutations \\
\hline
\end{tabular}

Adapted with permission from Baccarani et al. [29]. These definitions are an adaptation of the ELN definitions of response to firstline imatinib.

$\mathrm{NA}=$ Not applicable; $\mathrm{CCA} / \mathrm{Ph}+=$ clonal chromosome abnormalities in Philadelphia chromosome-positive cells; CHR = complete hematologic response; $\mathrm{CCA} / \mathrm{Ph}-=$ clonal chromosome abnormalities in Philadelphia chromosome-negative cells; CCyR = complete cytogenetic response; $\mathrm{MMR}=$ major molecular response $\left(\mathrm{BCR}-\mathrm{ABL} 1 \leq 0.1 \%=\mathrm{MR}^{3}\right.$ or better); $\mathrm{PCyR}=$ partial cytogenetic response.

${ }^{1}$ Optimal response: continue treatment.

${ }^{2}$ Suboptimal response/warning: monitor patients more carefully, some patients may benefit from change in therapy (no confirmed evidence that a change in therapy will improve response).

${ }^{3}$ Failure: change treatment.

${ }^{4}$ In two consecutive tests, of which one with a BCR-ABL1 transcripts level $\geq 1 \%$.

achieve a deeper response to therapy early has the potential to decrease the rate of transformation to AP/BP and other negative outcomes. In patients receiving secondline dasatinib after imatinib resistance or intolerance, those with an optimal versus suboptimal response versus treatment failure at 3 months had a higher probability of achieving CCyR (91, 51 and 9\%, respectively) and MMR (71, 31 and 5\%, respectively) within 2 years and a higher probability of 2-year OS (90, 80 and $67 \%$, respectively) and progression-free survival (PFS; 97, 93 and 88\%, respectively) [40]. In patients receiving second-line nilotinib after imatinib resistance or intolerance, those with a better than suboptimal versus suboptimal response versus treatment failure at 3 months had a higher probability of PFS at 12 months (93, 76 and $71 \%$, respectively) and 24 months $(79,59$ and $41 \%$, respectively) [39].

The lack of early response may be a surrogate marker for poorer long-term response and outcome. Early achievement of cytogenetic and/or molecular response can lead to subsequent improved responses and longterm outcomes in CML-CP [3, 48] (table 2). Several studies indicate that achievement of CCyR or MMR within 12 months is associated with a higher probability of sta-

Time to Change BCR-ABL Inhibitor Treatment in CML ble response, event-free survival (EFS), transformationfree survival, and OS $[3,6]$.

Reaching response milestones as early as 3 months from the initiation of BCR-ABL inhibitor treatment may further improve future responses and reduce transformation to advanced disease (table 3 ). In a study of patients receiving imatinib, the optimal predictive BCR-ABL transcript level cutoffs at 3, 6 and 12 months were established based on outcomes observed for the patient population, rather than using arbitrary predefined levels of $\log$ reduction. Data suggested that the transcript level cutoff of $\leq 9.84 \%$ at 3 months was the most informative for identifying patients with a high risk of progression and poor survival, compared with the 6- and 12-month cutoffs [46]. In patients treated with imatinib, achieving BCR-ABL transcript levels of $\leq 10 \%$ compared with $>10 \%$ at 3 months was associated with improved 8-year OS (93.3 vs. $56.9 \%$; $\mathrm{p}<0.001)$, improved 8 -year PFS (92.8 vs. $57.0 \%$; $\mathrm{p}<0.001)$, a lower risk of treatment failure by 18 months ( 5.8 vs. $20.7 \% ; \mathrm{p}=0.0003$ ), and a lower risk of disease progression ( 2.7 vs. $8.1 \%$; $p=0.0156$ ) [41, 46].

In a retrospective analysis of the phase III DASISION trial, achieving BCR-ABL transcript levels of $\leq 10 \%$ at 
Table 2. Probability of achieving MMR and the risk of developing a progression event according to reduction in BCR-ABL transcript levels at fixed time points [48]

\begin{tabular}{|c|c|c|c|c|c|c|}
\hline \multirow{2}{*}{$\begin{array}{l}B C R-A B L 1: A B L 1 \\
\text { transcript ratio }\end{array}$} & \multicolumn{6}{|c|}{ Percentage probability of outcome according to transcript ratio at specified time points } \\
\hline & 3 months & 6 months & 12 months & 3 months & 6 months & 12 months \\
\hline$\leq 0.1 \%$ & $100(3)$ & $96(6)$ & $97(12)$ & $4(13)$ & $1(38)$ & $3(40)$ \\
\hline$>0.1-1 \%$ & $84(6)$ & $69(12)$ & $61(18)$ & $3(46)$ & $7(30)$ & $2(48)$ \\
\hline$>1-10 \%$ & $53(17)$ & 44 (18) & $20(33)$ & $11(21)$ & $9(34)$ & $8(47)$ \\
\hline
\end{tabular}

Adapted with permission from Quintas-Cardama et al. [48]. Figures in parentheses are median months to outcome.

MMR = Major molecular response.

3 months, compared with levels of $>10 \%$, in both the dasatinib and imatinib arms, provided increased probability of achieving MMR by 2 years (dasatinib 76 and 16\%, imatinib 66 and 19\%, respectively), decreased risk of transformation to AP/BP CML within 3 years (dasatinib 3 and 14\%, imatinib 3 and $13 \%$, respectively) and increased probability of 3-year PFS (dasatinib 93 and 68\%, p = 0.0003; imatinib 96 and $75 \%, \mathrm{p}<0.0001$ ) and OS (dasatinib 96 and 86\%, $\mathrm{p}=0.0348$; imatinib 96 and $88 \%, \mathrm{p}=0.0036$, respectively) [44, 47]. Furthermore, deeper levels of response were achieved earlier with dasatinib compared with imatinib as equivalent BCR-ABL/ABL ratios were achieved 6 months earlier with dasatinib [44], and a higher proportion of patients treated with dasatinib achieved a BCR-ABL level of $\leq 10 \%$ at 3 months compared with imatinib ( 84 vs. $64 \%$, respectively) [44, 47]. Similar results were observed with earlier and deeper cytogenetic responses in DASISION [47]. In the phase III STI571 Prospective International Randomised Trial 2 (SPIRIT 2) study of dasatinib $100 \mathrm{mg}$ once daily versus imatinib $400 \mathrm{mg}$ once daily for newly diagnosed CML-CP, after a median follow-up of 18.4 months, an early and deep response with first-line dasatinib (BCR$\mathrm{ABL} \leq 10 \%$ after 3 months) was associated with an increased probability of eventually achieving a CCyR. Patients with $\leq 10 \%$ BCR-ABL levels at 3 months had significantly improved cumulative rates of CCyR, MMR and $\mathrm{MR}^{4.5}$ by 2 years [45]. BCR-ABL transcript cutoff levels predictive of long-term response with dasatinib were significantly lower compared with those for imatinib (e.g. 2 vs. 10\%), highlighting that response kinetics in patients receiving secondgeneration $\mathrm{BCR}-\mathrm{ABL}$ inhibitors may differ from those in patients receiving imatinib [45].

Similarly, in a retrospective analysis of the ENESTnd trial, a more rapid decline in BCR-ABL levels was also dem- onstrated. Median BCR-ABL levels for patients receiving nilotinib at 6 months (both arms; BCR-ABL ratio 0.19 IS) were similar to those for patients receiving imatinib at 18 months (BCR-ABL ratio $0.21 \mathrm{IS}$ ), and more patients receiving nilotinib 300 and $400 \mathrm{mg}$ twice daily had BCR-ABL levels of $\leq 10 \%$ at 3 months compared with patients receiving imatinib $(74,78$ and $61 \%$, respectively) $[31,43]$.

These retrospective studies indicate that early achievement of a response with BCR-ABL inhibitor therapies is predictive of improved long-term outcome and reduced risk of transformation to advanced disease (table 3). Delaying treatment response may decrease the chance of achieving these longer-term outcomes. For patients failing to achieve an early molecular or cytogenetic response, an early change in therapy to a second-line treatment may increase the probability of long-term response and survival. Based on these findings from retrospective analyses, NCCN and ESMO guidelines were updated to include provisions to allow change in treatment for patients failing to achieve BCR-ABL levels of $\leq 10 \%$ (or partial CyR) after 3 months of BCR-ABL inhibitor therapy (table $1 b, c)[28,29]$. The ELN recommendations suggest a change in treatment for patients failing to achieve BCRABL levels of $\leq 10 \%$ after 6 months of treatment (table $1 \mathrm{a}$ ) [30].

\section{Recommendations for Changing Treatment}

The ELN recommendations and the NCCN and ESMO guidelines recommend either imatinib $400 \mathrm{mg}$ once daily, dasatinib $100 \mathrm{mg}$ once daily or nilotinib $300 \mathrm{mg}$ twice daily for the first-line treatment of CML-CP [28-30]. For patients who are or become intolerant or resistant to first- 


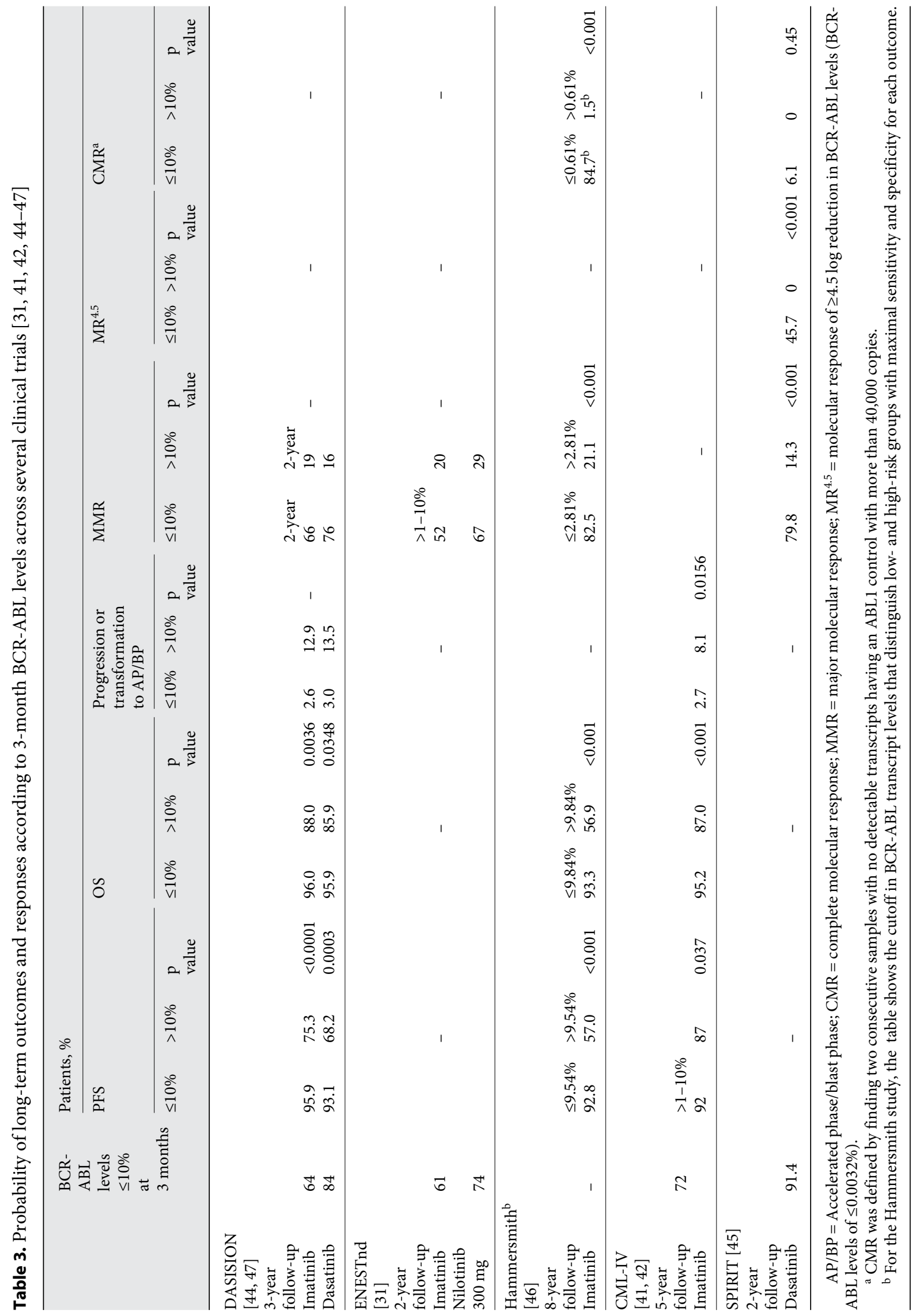


line BCR-ABL inhibitor treatment and do not achieve an optimal response, guidelines and recommendations suggest enrollment into a clinical trial, an increase in the imatinib dose, a change in BCR-ABL inhibitor therapy, or alloHSCT as alternative treatment options [28-30, 53, 54]. Given the recent data showing superior efficacy of nilotinib and dasatinib in patients with CML-CP, currently, high-dose imatinib has an uncertain role given the high rates of toxicity and risk of reduced adherence to treatment. AlloHSCT is a potentially curative treatment for patients with CML; however, considerable treatment-related mortality and morbidity and practical issues associated with alloHSCT, such as donor availability, have limited its utility. The tremendous long-term outcomes observed with first- and second-line BCR-ABL inhibitor therapy and the increasing number of available targeted therapies challenges the role of alloHSCT as second-line therapy.

Timing to initiation of a different BCR-ABL inhibitor following first-line treatment failure may affect longterm outcomes. Patients treated with dasatinib or nilotinib after cytogenetic relapse on imatinib have higher survival rates compared with patients treated after hematologic relapse (3-year survival: 92 vs. 52\%), supporting the idea that an early change of therapy may be advantageous although patients with hematologic relapse most likely have worse disease [55]. A retrospective analysis of imatinib-resistant patients receiving dasatinib attempted to establish the optimal time for initiating dasatinib after loss of response [56]. Overall, $72 \%$ of patients who received dasatinib after loss of a major cytogenetic response (MCyR) on imatinib achieved a CCyR compared with $42 \%$ of patients who were treated after loss of both MCyR and CHR. EFS was also higher after earlier dasatinib treatment (24-month EFS rates: 89\% after loss of MCyR on imatinib versus $29 \%$ after loss of both MCyR and CHR) [56]. An observational study (Factors Impacting on Response to Dasatinib in Europe) showed that in patients with CML-CP who had imatinib resistance/intolerance, delaying the time to dasatinib initiation negatively impacted the response to dasatinib [57]. A significant effect of time from imatinib failure to dasatinib initiation on the achievement of a better response to dasatinib was observed $(\mathrm{p}<0.023)$. Furthermore, a 6 - and 12-month delay in starting dasatinib resulted in a respective 7.5 and $14.4 \%$ decrease in the odds of achieving a better response (including CCyR/MMR). These studies suggest that optimal responses may be achieved earlier and the probability of improved long-term outcomes increased when a second-line BCR-ABL inhibitor is administered early after imatinib resistance or intolerance. Patients who have clinical indicators or surrogate markers for poor responses and outcomes on imatinib may also benefit from changing to a different BCR-ABL inhibitor earlier.

The presence of low-grade AEs in patients treated with imatinib may also influence the speed of remission and long-term outcome. For example, lowering the imatinib dose to manage such AEs in patients who reached specific levels of response but have persistent low-grade nonhematologic toxicities could potentially risk a loss of response. This provides a rationale for changing to an alternative therapy (dasatinib, nilotinib, bosutinib, ponatinib) in these patients rather than lowering the imatinib dose. However, it must be recognized that dasatinib, nilotinib, bosutinib, and ponatinib have their own specific AE profiles and there is always concern with changing an effective therapy, particularly if the low-grade AEs are not impeding adherence to the prescribed treatment regimen. With more treatment options available for CML-CP, it is more likely that physicians will alter treatment to improve quality of life especially as CML typically requires lifelong treatment [58].

For second-line treatment of CML, BCR-ABL inhibitor selection should be based on disease phase, primary or secondary resistance, mutations, likelihood of patient adherence, comorbidities, side effect profile, and physician experience [53]. BCR-ABL mutational analysis at the time of treatment failure provides additional guidance in the selection of optimal second-line BCR-ABL inhibitor therapy in patients with identifiable mutations; furthermore, mutation testing is recommended in patients experiencing treatment failure and before changing therapy to a second-line BCR-ABL inhibitor [28-30,53]. In patients with no identifiable mutations, the following should be considered when choosing second-line therapy: prior response to BCR-ABL inhibitors; BCR-ABL inhibitor used in the first-line setting; safety profile of each agent; comorbid conditions; likelihood of adherence to the prescribed regimen, and physician experience [28-30, 53]. In patients with a suboptimal response, but no identifiable imatinib-resistant mutations, imatinib dose escalation may be an option, but these patients should be closely monitored for toxicities. This option may become more favorable once imatinib becomes generically available, especially in patients with low-grade toxicities [59].

\section{Future Directions}

As noted, there are accumulating data to suggest that a change from imatinib therapy to second-generation BCR-ABL inhibitors in patients with suboptimal re- 
sponse may improve long-term responses and outcome; however, these data are retrospective and still immature. There is also no direct evidence that a change from imatinib therapy to dasatinib, nilotinib, bosutinib, or ponatinib can reverse the inferior prognosis of these patients and provide better responses and outcomes comparable with patients who received first-line treatment with the second-generation BCR-ABL inhibitor. An open-label, randomized, prospective, multi-center, phase IIb trial has been designed to assess the benefits of an early change from imatinib to dasatinib in patients with $>10 \%$ BCR-ABL levels at 3 months [60]. This study is being conducted in patients with CML-CP who have achieved CHR but have not achieved $\leq 10 \%$ BCR-ABL levels at 3 months after first-line treatment with imatinib $400 \mathrm{mg}$ once daily. Recruited patients are randomized to receive either dasatinib $100 \mathrm{mg}$ once daily or imatinib, with the option to dose increase following a standard of care approach. The rate of MMR at 12 months from the start of first-line imatinib has been established as the primary endpoint. This trial may prospectively identify patients who should change therapy early to achieve maximal molecular response and improved survival. In addition, the trial may serve as a steward of continued imatinib use in the first-line setting for patients who tolerate the drug and have $\leq 10 \%$ BCR-ABL levels after 3 months of treatment.

\section{Discussion}

Although most patients with newly diagnosed CML$\mathrm{CP}$ respond to imatinib, others experience resistance or intolerance necessitating a change in treatment. Delaying responses to imatinib (failing to achieve $\leq 10 \%$ BCR-ABL levels by 3 months or CCyR or MMR by 12 months) decreases PFS and OS and increases the risk of transformation to $\mathrm{AP} / \mathrm{BP}$ and the loss of response $[3,6,45,46]$.

\section{Changing Therapies}

Achieving early molecular and cytogenetic response is correlated with improved response and long-term outcomes. Changing therapies upon failure to reach early response landmarks may allow patients to achieve optimal responses earlier. A randomized trial will enable a prospective analysis of the potential benefits of changing treatment to dasatinib in patients not achieving $\leq 10 \%$ BCR-ABL levels after 3 months receiving imatinib. This will be of interest to physicians and payers and may guide future treatment recommendations.

Time to Change BCR-ABL Inhibitor

Treatment in CML
For some patients, optimal responses are achieved with imatinib but persistent low-grade or acute grade 3/4 AEs become a problem. AEs and intolerance can reduce adherence to treatment leading to decreased response and transformation to AP/BP [61]. For patients who experience low-grade chronic AEs with imatinib, two phase IV clinical trials are investigating changing therapy to dasatinib (NCT01660906; CA180-400) or nilotinib (NCT00980018; MAC S0999). It is hoped that AEs will improve or resolve with a change in therapy and an optimal response will be maintained.

\section{Beyond Second-Line Treatment}

Salvage therapy with alternative second-generation BCR-ABL inhibitors may be successful in patients who are resistant to second-line dasatinib or nilotinib, according to the different spectra of mutations associated with clinical resistance $[62,63]$. In a phase II study, patients who were resistant to both imatinib and dasatinib responded to third-line nilotinib treatment [64]. Similarly, bosutinib and ponatinib have demonstrated efficacy in patients who are resistant to imatinib and dasatinib and/ or nilotinib $[19,21,22,65,66]$. Ponatinib has shown activity in patients harboring the highly resistant T315I BCR-ABL mutation [22, 65, 66]. Other novel agents (SGX393 and PHA-739358) capable of inhibiting the T315I-mutated BCR-ABL are being developed [67, 68]. With more effective first-line therapy, fewer patients may require salvage.

\section{First-Line Treatment Selection}

Optimizing first-line treatment is essential to achieving better long-term outcomes [69]. Therapy should be tailored to ensure patients achieve a deep, early response associated with improved long-term survival. More patients achieve a deeper, faster response in the first-line setting with second-generation BCR-ABL inhibitors compared with imatinib $[23,24]$. Long-term follow-up is needed to determine if this correlates with a survival benefit and an improvement in PFS. Once generic imatinib is available, one possibility to reduce treatment cost may be identifying subgroups of patients who have poorer outcomes on imatinib who might derive greater benefit using dasatinib or nilotinib as first-line treatments.

\section{Final Considerations}

In both second- and first-line settings, choosing between dasatinib and nilotinib requires consideration on a patient-to-patient basis, as there is no comparative clinical trial evidence to direct this decision. Economic con- 
siderations are anticipated to become a significant factor for treatment selection when generic imatinib becomes available in 2015 . A prospective early change trial would help define a population of patients with equivalent response and survival when continuing on imatinib treatment compared with changing to a second-generation BCR-ABL inhibitor. For the remaining patients, this trial would present definitive evidence for the required level and timing of response, indicating a need to change from imatinib to a more potent BCR-ABL inhibitor and thus providing the best possibility of achieving improved long-term outcomes.

\section{Acknowledgements}

Professional medical writing support and editorial assistance was provided by StemScientific, funded by Bristol-Myers Squibb.

\section{Disclosure Statement}

Dr. Savona has no conflicts of interest to declare.

Dr. Saglio has provided a scientific consultancy role for BristolMyers Squibb, Novartis and Pfizer and is a member of the Speaker Bureau for Bristol-Myers Squibb, Novartis, Pfizer, and Ariad.

\section{References}

1 Hughes TP, Kaeda J, Branford S, Rudzki Z, Hochhaus A, Hensley ML, Gathmann I, Bolton AE, van Hoomissen IC, Goldman JM, Radich JP, International Randomised Study of Interferon versus STI571 (IRIS) Study Group: Frequency of major molecular responses to imatinib or interferon alfa plus cytarabine in newly diagnosed chronic myeloid leukemia. N Engl J Med 2003;349:1423-1432.

-2 O'Brien SG, Guilhot F, Larson RA, Gathmann I, Baccarani M, Cervantes F, Cornelissen JJ, Fischer T, Hochhaus A, Hughes T, Lechner K, Nielsen JL, Rousselot P, Reiffers J, Saglio G, Shepherd J, Simonsson B, Gratwohl A, Goldman JM, Kantarjian H, Taylor K, Verhoef G, Bolton AE, Capdeville R, Druker BJ, IRIS Investigators: Imatinib compared with interferon and low dose cytarabine for newly diagnosed chronic-phase chronic myeloid leukemia. N Engl J Med 2003;348:994-1004.

3 Deininger M, O'Brien SG, Guilhot F, Goldman JM, Hochhaus A, Hughes TP, Radich JP, Hatfield AK, Mone M, Filian J, Reynolds J, Gathmann I, Larson RA, Druker BJ: International Randomized Study of Interferon vs STI571 (IRIS) 8-year follow up: sustained survival and low risk for progression or events in patients with newly diagnosed chronic myeloid leukemia in chronic phase (CML-CP) treated with imatinib (abstract 1126). Blood 2009;114(suppl).

-4 Druker BJ, Guilhot F, O’Brien S, Gathmann I, Kantarjian H, Gattermann N, Deininger MW, Silver RT, Goldman JM, Stone RM, Cervantes F, Hochhaus A, Powell BL, Gabrilove JL, Rousselot P, Reiffers J, Cornelissen JJ, Hughes T, Agis H, Fischer T, Verhoef G, Shepherd J, Saglio G, Gratwohl A, Nielsen JL, Radich JP, Simonsson B, Taylor K, Baccarani $M$, So C, Letvak L, Larson RA, IRIS Investigators: Five-year follow-up of patients receiving imatinib for chronic myeloid leukemia. $\mathrm{N}$ Engl J Med 2006;355:2408-2417.

5 Chronic Myeloid Leukemia Trialists' Collaborative Group: Interferon-alfa versus chemotherapy for chronic myeloid leukemia: a me- ta-analysis of seven randomized trials. J Natl Cancer Inst 1997;89:1616-1620.

-6 de Lavallade H, Apperley JF, Khorashad JS, Milojkovic D, Reid AG, Bua M, Szydlo R, Olavarria E, Kaeda J, Goldman JM, Marin D: Imatinib for newly diagnosed patients with chronic myeloid leukemia: incidence of sustained responses in an intention-to-treat analysis. J Clin Oncol 2008;26:3358-3363.

7 Lucas CM, Wang L, Austin GM, Knight K, Watmough SJ, Shwe KH, Dasgupta R, Butt NM, Galvani D, Hoyle CF, Seale JR, Clark RE: A population study of imatinib in chronic myeloid leukaemia demonstrates lower efficacy than in clinical trials. Leukemia 2008;22: 1963-1966.

-8 Hochhaus A, O'Brien SG, Guilhot F, Druker BJ, Branford S, Foroni L, Goldman JM, Müller MC, Radich JP, Rudoltz M, Mone M, Gathmann I, Hughes TP, Larson RA, IRIS Investigators: Six-year follow-up of patients receiving imatinib for the first-line treatment of chronic myeloid leukemia. Leukemia 2009; 23:1054-1061.

-9 Boschelli DH, Ye F, Wang YD, Dutia M, Johnson SL, Wu B, Miller K, Powell DW, Yaczko D, Young M, Tischler M, Arndt K, Discafani C, Etienne C, Gibbons J, Grod J, Lucas J, Weber JM, Boschelli F: Optimization of 4-phenylamino-3-quinolinecarbonitriles as potent inhibitors of Src kinase activity. J Med Chem 2001;44:3965-3977.

10 Lombardo LJ, Lee FY, Chen P, Norris D, Barrish JC, Behnia K, Castaneda S, Cornelius LA, Das J, Doweyko AM, Fairchild C, Hunt JT, Inigo I, Johnston K, Kamath A, Kan D, Klei H, Marathe P, Pang S, Peterson R, Pitt S, Schieven GL, Schmidt RJ, Tokarski J, Wen ML, Wityak J, Borzilleri RM: Discovery of N-(2-chloro6-methyl-phenyl)-2-(6-(4-(2-hydroxyethyl)piperazin-1-yl)-2-methylpyrimidin-4-ylamino)thiazole-5-carboxamide (BMS-354825), a dual Src/Abl kinase inhibitor with potent antitumor activity in preclinical assays. J Med Chem 2004;47:6658-6661.
1 O'Hare T, Walters DK, Stoffregen EP, Jia T, Manley PW, Mestan J, Cowan-Jacob SW, Lee FY, Heinrich MC, Deininger MW, Druker BJ: In vitro activity of $\mathrm{Bcr}-\mathrm{Abl}$ inhibitors $\mathrm{AMN} 107$ and BMS-354825 against clinically relevant imatinib-resistant Abl kinase domain mutants. Cancer Res 2005;65:4500-4505.

12 Puttini M, Coluccia AM, Boschelli F, Cleris L, Marchesi E, Donella-Deana A, Ahmed S, Redaelli S, Piazza R, Magistroni V, Andreoni F, Scapozza L, Formelli F, Gambacorti-Passerini C: In vitro and in vivo activity of SKI-606, a novel Src-Abl inhibitor, against imatinib-resistant Bcr-Abl+ neoplastic cells. Cancer Res 2006;66:11314-11322.

13 Redaelli S, Piazza R, Rostagno R, Magistroni V, Perini P, Marega M, Gambacorti-Passerini C, Boschelli F: Activity of bosutinib, dasatinib, and nilotinib against 18 imatinib-resistant BCR/ ABL mutants. J Clin Oncol 2009;27:469-471.

14 Schittenhelm MM, Shiraga S, Schroeder A, Corbin AS, Griffith D, Lee FY, Bokemeyer C, Deininger MW, Druker BJ, Heinrich MC: Dasatinib (BMS-354825), a dual SRC/ABL kinase inhibitor, inhibits the kinase activity of wildtype, juxtamembrane, and activation loop mutant KIT isoforms associated with human malignancies. Cancer Res 2006;66:473-481.

15 Weisberg E, Manley PW, Breitenstein W, Brüggen J, Cowan-Jacob SW, Ray A, Huntly B, Fabbro D, Fendrich G, Hall-Meyers E, Kung AL, Mestan J, Daley GQ, Callahan L, Catley L, Cavazza C, Azam M, Neuberg D, Wright RD, Gilliland DG, Griffin JD: Characterization of AMN107, a selective inhibitor of native and mutant Bcr-Abl. Cancer Cell 2005;7:129-141.

16 Brave M, Goodman V, Kaminskas E, Farrell A, Timmer W, Pope S, Harapanhalli R, Saber H, Morse D, Bullock J, Men A, Noory C, Ramchandani R, Kenna L, Booth B, Gobburu J, Jiang X, Sridhara R, Justice R, Pazdur R: Sprycel for chronic myeloid leukemia and Philadelphia chromosome-positive acute lymphoblastic leukemia resistant to or intolerant of imatinib mesylate. Clin Cancer Res 2008;14:352-359. 
17 SPRYCEL (prescribing information). Princeton, Bristol-Myers Squibb, 2012.

18 Hazarika M, Jiang X, Liu Q, Lee SL, Ramchandani R, Garnett C, Orr MS, Sridhara R, Booth B, Leighton JK, Timmer W, Harapanhalli R, Dagher R, Justice R, Pazdur R: Tasigna for chronic and accelerated phase Philadelphia chromosome - positive chronic myelogenous leukemia resistant to or intolerant of imatinib. Clin Cancer Res 2008;14:5325-5331.

19 Khoury HJ, Cortes JE, Kantarjian HM, Gambacorti-Passerini C, Baccarani M, Kim DW, Zaritskey A, Countouriotis A, Besson N, Leip $\mathrm{E}$, Kelly V, Brümmendorf TH: Bosutinib is active in chronic phase chronic myeloid leukemia after imatinib and dasatinib and/or nilotinib therapy failure. Blood 2012;119:3403-3412.

20 Tasigna (prescribing information). East Hanover, Novartis Pharmaceuticals Corporation, 2012.

21 Bosulif (prescribing information). New York, Pfizer, 2012.

22 Iclusig (prescribing information). Cambridge, ARIAD Pharmaceuticals, 2012.

-23 Kantarjian H, Shah NP, Hochhaus A, Cortes J, Shah S, Ayala M, Moiraghi B, Shen Z, Mayer J, Pasquini R, Nakamae H, Huguet F, Boqué $\mathrm{C}$, Chuah C, Bleickardt E, Bradley-Garelik MB, Zhu C, Szatrowski T, Shapiro D, Baccarani M: Dasatinib versus imatinib in newly diagnosed chronic-phase chronic myeloid leukemia. N Engl J Med 2010;362:2260-2270.

-24 Saglio G, Kim D-W, Issaragrisil S, le Coutre P, Etienne G, Lobo C, Pasquini R, Clark RE, Hochhaus A, Hughes TP, Gallagher N, Hoenekopp A, Dong M, Haque A, Larson RA, Kantarjian HM, ENESTnd Investigators: Nilotinib versus imatinib for newly diagnosed chronic myeloid leukemia. N Engl J Med 2010;362:2251-2259.

-25 Kantarjian HM, Shah NP, Cortes JE, Baccarani $M$, Agarwal MB, Undurraga MS, Wang J, Ipiña JJ, Kim DW, Ogura M, Pavlovsky C, Junghanss C, Milone JH, Nicolini FE, Robak T, Van Droogenbroeck J, Vellenga E, Bradley-Garelik MB, Zhu C, Hochhaus A: Dasatinib or imatinib in newly diagnosed chronicphase chronic myeloid leukemia: 2-year follow-up from a randomized phase 3 trial (DASISION). Blood 2012;119:1123-1129.

26 Hochhaus A, Shah N, Cortes J, Baccarani M, Bradley-Garelik MB, Dejardin D, Kantarjian $\mathrm{H}$ : Dasatinib versus imatinib (IM) in newly diagnosed chronic myeloid leukemia in chronic phase (CML-CP): DASISION 3-year follow-up (abstract 6504). J Clin Oncol 2012; 15(suppl 1).

-27 Kantarjian HM, Hochhaus A, Saglio G, De Souza C, Flinn IW, Stenke L, Goh YT, Rosti G, Nakamae H, Gallagher NJ, Hoenekopp A, Blakesley RE, Larson RA, Hughes TP: Nilotinib versus imatinib for the treatment of patients with newly diagnosed chronic phase, Philadelphia chromosome-positive, chronic myeloid leukaemia: 24-month minimum follow-up of the phase 3 randomised ENESTnd trial. Lancet Oncol 2011;12:841-851.
28 National Comprehensive Cancer Network: NCCN Clinical Practice Guidelines in Oncology $^{\mathrm{TM}}$. Chronic myelogenous leukemia v.3.2013. http://www.nccn.org/professionals/ physician_gls/f_guidelines.asp\#site.

29 Baccarani M, Pileri S, Steegmann JL, Muller M, Soverini S, Dreyling M, on behalf of the ESMO Guidelines Working Group: Chronic myeloid leukemia: ESMO clinical practice guidelines for diagnosis, treatment, and follow-up. Ann Oncol 2012;23(suppl 7):vii72-vii73.

30 Baccarani M, Deininger MW, Rosti G, Hochhaus A, Soverini S, Apperley JF, Cervantes F, Clark RE, Cortes JE, Guilhot F, Hjorth-Hansen H, Hughes TP, Kantarjian HM, Kim D-W, Larson RA, Lipton JH, Mahon F-X, Martinelli G, Mayer J, Müller MC, Niederwieser D, Pane F, Radich JP, Rousselot P, Saglio G, Saußele S, Schiffer C, Silver R, Simonsson B, Steegmann J-L, Goldman JM, Rüdiger H: European LeukemiaNet recommendations for the management of chronic myeloid leukemia: 2013. Blood 2013; ePub ahead of print, DOI: 10.1182/blood-2013-05-501569.

31 Kantarjian HM, Flinn IW, Goldberg S, Bunworasate U, Zanichelli MA, Nakamae $\mathrm{H}$, Hughes TP, Hochhaus A, Saglio G, Woodman RC, Blakesley RE, Kemp CN, Kalaycio ME, Larson RA: Nilotinib versus imatinib in patients with newly diagnosed chronic myeloid leukemia in chronic phase (CML-CP): ENESTnd 3-year follow-up (abstract 6509). J Clin Oncol 2012;30(suppl).

32 Larson RA, Hochhaus A, Hughes TP, Clark RE, Etienne G, Kim DW, Flinn IW, Kurokawa M, Moiraghi B, Yu R, Blakesley RE, Gallagher NJ, Saglio G, Kantarjian HM: Nilotinib vs imatinib in patients with newly diagnosed Philadelphia chromosome-positive chronic myeloid leukemia in chronic phase: ENESTnd 3-year follow-up. Leukemia 2012;26:21972203.

33 Calabretta B, Perrotti D: The biology of CML blast crisis. Blood 2004;103:4010-4022.

34 Cortes J, O'Dwyer ME: Clonal evolution in chronic myelogenous leukemia. Hematol Oncol Clin North Am 2004; 18:671-684.

35 Goldman JM, Melo JV: Targeting the BCR$\mathrm{ABL}$ tyrosine kinase in chronic myeloid leukemia. N Engl J Med 2001;344:1084-1086.

36 Hehlmann R, Saussele S: Treatment of chronic myeloid leukemia in blast crisis. Haematologica 2008;93:1765-1769.

37 Soverini S, Martinelli G, Rosti G, Bassi S, Amabile M, Poerio A, Giannini B, Trabacchi E, Castagnetti F, Testoni N, Luatti S, de Vivo A, Cilloni D, Izzo B, Fava M, Abruzzese E, Alberti D, Pane F, Saglio G, Baccarani M: ABL mutations in late chronic phase chronic myeloid leukemia patients with up-front cytogenetic resistance to imatinib are associated with a greater likelihood of progression to blast crisis and shorter survival: a study by the GIMEMA Working Party on Chronic Myeloid Leukemia. J Clin Oncol 2005;23:4100-4109.

38 Khorashad JS, de Lavallade H, Apperley JF, Milojkovic D, Reid AG, Bua M, Szydlo R, Ola- varria E, Kaeda J, Goldman JM, Marin D: Finding of kinase domain mutations in patients with chronic phase chronic myeloid leukemia responding to imatinib may identify those at high risk of disease progression. J Clin Oncol 2008;26:4806-4813.

39 Baccarani M, Giles F, Ottmann O, Reynolds J, Woodman R, le Coutre P, Kantarjian H: Long-term outcome (progression-free survival) in patients receiving nilotinib for imatinib failure who meet suboptimal response criteria according to European LeukemiaNet 2009 CML recommendations (abstract 0132). Haematologica 2010;95(suppl 2):53.

40 Cortes JE, Shah NP, Schiffer CA, LeCoutre PD, Saglio G, Quintás-Cardama A, Kantarjian $\mathrm{H}$, Jabbour E, Bahceci E, Chen A, Lambert A, Guilhot F: Significance of ELN provisional response definitions in predicting long-term outcomes of patients with CP-CML treated with dasatinib after imatinib failure (abstract 3439). Blood 2010;116(suppl).

41 Hanfstein B, Müller MC, Erben P, Schnittger S, Saussele S, Leitner A, Proetel U, Ehninger G, Hossfeld DK, Kolb H-J, Krause SW, Nerl C, Pralle H, Heim D, Baerlocher GM, Heimpel H, Hehlmann R, Hochhaus A, The German CML-Study Group: Molecular response after 3 months of 1st-line imatinib therapy is predictive for treatment failure and disease progression in patients with chronic phase chronic myeloid leukemia - a followup analysis of the German CML study IV (abstract 360). Blood 2010;116(suppl).

42 Hanfstein B, Müller MC, Hehlmann R, Erben $P$, Lauseker M, Fabarius A, Schnittger S, Haferlach C, Göhring G, Proetel U, Kolb HJ, Krause SW, Hofmann WK, Schubert J, Einsele $H$, Dengler J, Hänel $M$, Falge C, Kanz L, Neubauer A, Kneba M, Stegelmann F, Pfreundschuh M, Waller CF, Branford S, Hughes TP, Spiekermann K, Baerlocher GM, Pfirrmann M, Hasford J, Saussele S, Hochhaus A, SAKK, German CML Study Group: Early molecular and cytogenetic response is predictive for long-term progression-free and overall survival in chronic myeloid leukemia (CML). Leukemia 2012;26: 2096-2102.

43 Hochhaus A, Saglio G, Larson RA, Kim D-W, Flinn IW, Goh Y-T, Dorlhiac-Llacer PE, Porkka K, Kurokawa M, DeSouza C, Shou Y, Gallagher NJ, Haque A, Kantarjian H, Hughes TP: Nilotinib lowers the incidence of BCRABL mutations and improves the molecular response kinetics compared with imatinib in patients (pts) with newly diagnosed chronic myeloid leukemia (CML) (abstract 3431). Blood 2010;116(suppl).

44 Hochhaus A, Boqué C, Bradley Garelik MB, Manos G, Steegmann JL: Molecular response kinetics and $\mathrm{BCR}-\mathrm{ABL}$ reductions in patients with newly diagnosed chronic myeloid leukemia in chronic phase (CML-CP) receiving dasatinib versus imatinib: DASISION 3-year follow-up (abstract 0192). Haematologica 2012;97(suppl 1). 
45 Marin D, Hedgley C, Clark RE, Apperley J, Foroni L, Milojkovic D, Pocock C, Goldman JM, O’Brien S: Predictive value of early molecular response in patients with chronic myeloid leukemia treated with first-line dasatinib. Blood 2012;120:291-294.

-46 Marin D, Ibrahim AR, Lucas C, Gerrard G, Wang L, Szydlo RM, Clark RE, Apperley JF, Milojkovic D, Bua M, Pavlu J, Paliompeis C, Reid A, Rezvani K, Goldman JM, Foroni L: Assessment of $B C R-A B L 1$ transcript levels at 3 months is the only requirement for predicting outcome for patients with chronic myeloid leukemia treated with tyrosine kinase inhibitors. J Clin Oncol 2012;30: 232-238.

47 Saglio G, Kantarjian HM, Shah N, Jabbour EJ, Quintas-Cardama A, Steegmann JL, Boqué C, Chuah C, Pavlovsky C, Mayer J, Ukropec J, Wildgust M, Hochhaus A: Early response (molecular and cytogenetic) and long-term outcomes in newly diagnosed chronic myeloid leukemia in chronic phase (CML-CP): exploratory analysis of DASISION 3-year data (abstract 1675). Blood 2012;120(suppl).

-48 Quintas-Cardama A, Kantarjian H, Jones D, Shan J, Borthakur G, Thomas D, Kornblau S, O’Brien S, Cortes J: Delayed achievement of cytogenetic and molecular response is associated with increased risk of progression among patients with chronic myeloid leukemia in early chronic phase receiving high-dose or standard-dose imatinib therapy. Blood 2009; 113:6315-6321.

-49 Marin D, Milojkovic D, Olavarria E, Khorashad JS, de Lavallade H, Reid AG, Foroni L, Rezvani K, Bua M, Dazzi F, Pavlu J, Klammer M, Kaeda JS, Goldman JM, Apperley JF: European LeukemiaNet criteria for failure or suboptimal response reliably identify patients with CML in early chronic phase treated with imatinib whose eventual outcome is poor. Blood 2008; 112:4437-4444.

50 Alvarado Y, Kantarjian H, O'Brien S, Faderl S, Borthakur G, Burger J, Wierda W, GarciaManero G, Shan J, Cortes J: Significance of suboptimal response to imatinib, as defined by the European LeukemiaNet, in the longterm outcome of patients with early chronic myeloid leukemia in chronic phase reference. Cancer 2009;115:3709-3718.

51 Breccia M, Orlandi SM, Latagliata R, Grammatico S, Diverio D, Mancini M, Loglisci G, Salaroli A, Federico V, Santopietro M, Alimena G: Suboptimal response to imatinib according to 2006-2009 European LeukaemiaNet criteria: a 'grey zone' at 3, 6 and 12 months identifies chronic myeloid leukaemia patients who need early intervention. $\mathrm{Br} \mathrm{J}$ Haematol 2011;152:119-121.

-52 Baccarani M, Cortes J, Pane F, Niederwieser D, Saglio G, Apperley J, Cervantes F, Deininger M, Gratwohl A, Guilhot F, Hochhaus A, Horowitz M, Hughes T, Kantarjian H, Larson R, Radich J, Simonsson B, Silver RT, Goldman J, Hehlmann R, European LeukemiaNet: Chronic myeloid leukemia: an up- date of concepts and management recommendations of European LeukemiaNet. J Clin Oncol 2009;27:6041-6051.

53 O'Brien S, Berman E, Moore JO, Pinilla-Ibarz J, Radich JP, Shami PJ, Smith BD, Snyder DS, Sundar HM, Talpaz M, Wetzler M: NCCN Task Force report: tyrosine kinase inhibitor therapy selection in the management of patients with chronic myelogenous leukemia. J Natl Compr Canc Netw 2011;9(suppl 2):S1-S25.

54 Yeung T, Osborn P, White L, Branford S, Kornhauser M, Slader A, Hiwase K, Hertzberg S, Schwarer P, Filshie J, Arthur K, Kwan L, Forsyth J, Ross D, Mills A, Grigg P, Hughes P: CML patients failing to achieve MMR by 12 months may benefit from dose escalation or switching to nilotinib: a 24 month update of results from the TIDEL-II trial (abstract 0137). Haematologica 2011;96(suppl 2):55.

55 Kantarjian H, O'Brien S, Talpaz M, Borthakur G, Ravandi F, Faderl S, Verstovsek S, Rios MB, Shan J, Giles F, Cortes J: Outcome of patients with Philadelphia chromosome-positive chronic myelogenous leukemia postimatinib mesylate failure. Cancer 2007;109: 1556-1560.

56 Quintas-Cardama A, Cortes JE, O'Brien S, Ravandi F, Borthakur G, Liu D, Bleickardt E, Chen TT, Kantarjian HM: Dasatinib early intervention after cytogenetic or hematologic resistance to imatinib in patients with chronic myeloid leukemia. Cancer 2009;115: 2912-2921.

57 Morra E, Michallet M, Marin D, Hellmann A, Niederwieser D, Schlöegl E, Björeman M, Foryciarz K, Ho A, Kuliczkowski K, Ossenkoppele G, Gozzini A, Gora-Tybor J, Guerra L, Verhoef G: Delaying the initiation of dasatinib after imatinib failure has a negative impact on CP-CML patients outcome: results from a European observational study (FORTE; CA180-211) (abstract 0701). Haematologica 2011;96(suppl 2).

58 Pinilla-Ibarz J, Cortes J, Mauro MJ: Intolerance to tyrosine kinase inhibitors in chronic myeloid leukemia: definitions and clinical implication. Cancer 2011;117:688-697.

59 Rudzki J, Wolf D: Dose escalation of imatinib in chronic-phase chronic myeloid leukemia patients: is it still reasonable? Expert Rev Hematol 2011;4:153-159.

60 Bristol-Myers Squibb: ClinicalTrials.gov. NLM identifier: NCT01593254. Bethesda, National Library of Medicine (US), 2000present.

61 Marin D, Bazeos A, Mahon FX, Eliasson L, Milojkovic D, Bua M, Apperley JF, Szydlo R, Desai R, Kozlowski K, Paliompeis C, Latham V, Foroni L, Molimard M, Reid A, Rezvani K, de Lavallade H, Guallar C, Goldman J, Khorashad JS: Adherence is the critical factor for achieving molecular responses in patients with chronic myeloid leukemia who achieve complete cytogenetic responses on imatinib. J Clin Oncol 2010; 28:2381-2388.
62 Barańska M, Lewandowski K, Gniot M, Iwoła M, Lewandowska M, Komarnicki M: Dasatinib treatment can overcome imatinib and nilotinib resistance in CML patient carrying F359I mutation of BCR-ABL oncogene. J Appl Genet 2008;49:201-203.

63 Kim D, Kim DW, Cho BS, Goh HG, Kim SH, Kim WS, Lee J, Kweon IY, Park SH, Yoon JH, Kim ND, Chun H: Structural modeling of V299L and E459K Bcr-Abl mutation, and sequential therapy of tyrosine kinase inhibitors for the compound mutations. Leuk Res 2009; 33:1260-1265.

64 Giles FJ, Abruzzese E, Rosti G, Kim DW, Bhatia R, Bosly A, Goldberg S, Kam GL, Jagasia M, Mendrek W, Fischer T, Facon T, Dünzinger U, Marin D, Mueller MC, Shou Y, Gallagher NJ, Larson RA, Mahon FX, Baccarani M, Cortes J, Kantarjian HM: Nilotinib is active in chronic and accelerated phase chronic myeloid leukemia following failure of imatinib and dasatinib therapy. Leukemia 2010; 24:1299-1301.

65 Cortes JE, Kim DW, Pinilla-Ibarz J, Paquette R, le Coutre PD, Chuah C, Nicolini FE, Apperley J, Khoury HJ, Talpaz M, DePersio JF, DeAngelo DJ, Rea D, Abruzzese E, Müller MC, Baccarani M, Gambacorti-Passerini C, Turner CD, Haluska FG, Kantarjian H: PACE: a pivotal phase II trial of ponatinib in patients with CML and Ph+ ALL resistant or intolerant to dasatinib or nilotinib, or with the T315I mutation (abstract 6503). J Clin Oncol 2012;30(suppl).

66 O'Hare T, Shakespeare WC, Zhu X, Eide CA, Rivera VM, Wang F, Adrian LT, Zhou T, Huang WS, Xu Q, Metcalf CA 3rd, Tyner JW, Loriaux MM, Corbin AS, Wardwell S, Ning Y, Keats JA, Wang Y, Sundaramoorthi R, Thomas M, Zhou D, Snodgrass J, Commodore L, Sawyer TK, Dalgarno DC, Deininger MW, Druker BJ, Clackson T: AP24534, a pan-BCR-ABL inhibitor for chronic myeloid leukemia, potently inhibits the T315I mutant and overcomes mutationbased resistance. Cancer Cell 2009; 16: 401-412.

-67 Gontarewicz A, Balabanov S, Keller G, Colombo R, Graziano A, Pesenti E, Benten D, Bokemeyer C, Fiedler W, Moll J, BrümmendorfTH: Simultaneous targeting of Aurora kinases and Bcr-Abl kinase by the small molecule inhibitor PHA-739358 is effective against imatinib-resistant BCR-ABL mutations including T315I. Blood 2008; 111:4355-4364.

-68 O’Hare T, Eide CA, Tyner JW, Corbin AS, Wong MJ, Buchanan S, Holme K, Jessen KA, Tang C, Lewis HA, Romero RD, Burley SK, Deininger MW: SGX393 inhibits the CML mutant Bcr-AblT315I and preempts in vitro resistance when combined with nilotinib or dasatinib. Proc Natl Acad Sci USA 2008; 105: 5507-5512.

69 Cortes JE: Not only response but early response to tyrosine kinase inhibitors in chronic myeloid leukemia. J Clin Oncol 2012;30: 223-224. 